Instituto Internacional de Investigación y Desarrollo Tecnológico Educativo INDTEC, C.A.

DOI: https://doi.org/10.29394/Scientific.issn.2542-2987.2021.6.21.18.336-355

OAI-PMH: http://www.indteca.com/ojs/index.php/Revista Scientific/oai

Ensayo Original / Original Essay

\title{
La revalorización de la identidad cultural: Un análisis retrospectivo de las principales culturas del Ecuador
}

\author{
Autores: María Elena Guerrero Salazar \\ Universidad de Guayaquil, UG \\ maria.guerreros@ug.edu.ec \\ Guayaquil, Ecuador \\ https://orcid.org/0000-0002-0506-7509 \\ Verónica Paulina Pilaquinga Cantuña \\ Agencia de Regulación y Control Fito y Zoosanitario, AGROCALIDAD \\ veronica.pilaquinga@agrocalidad.gob.ec \\ Guayaquil, Ecuador \\ https://orcid.org/0000-0002-3059-8248 \\ Christian Virgilio Guerrero Salazar \\ Asesoría y capacitación pedagógica, ASCAPED \\ chguerrero.ascaped@gmail.com \\ Guayaquil, Ecuador \\ https://orcid.org/0000-0003-3108-1846
}

\section{Resumen}

La identidad cultural es lo que hace ricos a los pueblos de una nación, es por ello que el Estado debe invertir en el rescate de su biodiversidad, cultura, tradiciones y gastronomía; se debe revalorizar el legado que dejan los antepasados y no permitir que se desvanezca lo que por derecho les pertenece. Este ensayo académico está basado en la revisión de fuentes documentales, en el mismo se observa las posturas de los arqueólogos, historiadores e investigadores que estudiaron las culturas ecuatorianas como es el caso de Meyers (1998); Holm (1981); Ayala (2017); Perez (1975); y Pazos (2008), entre otros. Se busca conocer más profundamente las prácticas culturales, agrícolas, y gastronómicas de las culturas Milagro Quevedo y Manteño Huancavilca, de la región costa; la cultura Caranqui de la región sierra y Shuar del oriente ecuatoriano, y los vestigios culturales que nos heredaron, para analizar desde un punto de vista valorativo la relación existente entre la naturaleza y el hombre, así como las costumbres que, a pesar de los años se mantienen vigentes en nuestra sociedad, formando las tradiciones ancestrales que dignifican nuestro origen como pueblo latinoamericano y dan sentido a la diversidad cultural de nuestro país.

Palabras claves: identidad cultural; biodiversidad; costumbres; tradiciones.

Código de clasificación internacional: 6301.01 - Evolución cultural.

Cómo citar este ensayo:

Guerrero, M., Pilaquinga, V., \& Guerrero, C. (2021). La revalorización de la identidad cultural: Un análisis retrospectivo de las principales culturas del Ecuador. Revista Scientific, 6(21), 336-355, e-ISSN: 2542-2987. Recuperado de: https://doi.org/10.29394/Scientific.issn.25422987.2021.6.21.18.336-355

Fecha de Recepción: 10-03-2021
Fecha de Aceptación: 10-07-2021
Fecha de Publicación: 05-08-2021 
Ensayo Original / Original Essay

\section{The revaluation of cultural identity: A retrospective analysis of the main cultures of Ecuador}

\begin{abstract}
Cultural identity is what makes the peoples of a nation rich, which is why the State must invest in rescuing their biodiversity, culture, traditions and gastronomy; The legacy left by the ancestors must be revalued and what rightfully belongs to them must not be allowed to vanish. This academic essay is based on the review of documentary sources, in it the positions of archaeologists, historians and researchers who studied Ecuadorian cultures are observed, as is the case of Meyers (1998); Holm (1981); Ayala (2017); Perez (1975); and Pazos (2008), among others. It seeks to know more deeply the cultural, agricultural, and gastronomic practices of the Milagro Quevedo and Manteño Huancavilca cultures, of the coastal region; the Caranqui culture of the Sierra and Shuar region of eastern Ecuador, and the cultural vestiges that were inherited from us, to analyze from an evaluative point of view the relationship between nature and man, as well as the customs that, despite the years remain valid in our society, forming the ancestral traditions that dignify our origin as a Latin American people and give meaning to the cultural diversity of our country.
\end{abstract}

Keywords: cultural identity; biodiversity; customs; traditions. International classification code: 6301.01 - Cultural evolution.
How to cite this essay:

Guerrero, M., Pilaquinga, V., \& Guerrero, C. (2021). The revaluation of cultural identity: A retrospective analysis of the main cultures of Ecuador. Revista Scientific, 6(21), 336-355, e-ISSN: 2542-2987. Recovered from: https://doi.org/10.29394/Scientific.issn.2542-2987.2021.6.21.18.336355
Date Received:

10-03-2021
Date Acceptance:

10-07-2021
Date Publication: 05-08-2021 


\section{Introducción}

Para poder introducirse en el tema de revalorización primero se debe entender lo que significa la pérdida de la identidad, y para ello es importante tener un punto de partida bien establecido, como es el de reconocer qué es cultura e identidad, y qué contexto abarca cada una de ellas. Cuando se habla de cultura se menciona todo aquello que le da valor a un grupo o sociedad. De acuerdo con Ron (1977):

Tylor, en 1.871, definía la cultura como "ese todo complejo que comprende el conocimiento, las creencias, el arte, la moral, la ley, la costumbre y otras facultades y hábitos adquiridos por el hombre en cuanto miembro de la sociedad". Esta definición que expresaría el punto de vista del evolucionismo, se ha sintetizado en la afirmación de que la cultura comprende toda clase de comportamiento aprendido (pág. 13).

Se deduce que hablar de cultura no solo constituye mencionar características personales que identifican al individuo como tal, sino que engloba también a aquellas características comunes que le permiten relacionarse con otras personas, entre las que se encuentran: el dialecto, comportamiento, vestimenta, historia, ideas, tradiciones, hábitos, folklore, entre otras. Sin embargo, la cultura también comprende a la naturaleza en que se desenvuelve un individuo, así lo menciona Eagleton (2000): al indicar que la cultura es un concepto derivado de la naturaleza que implica "producción», es decir un control del desarrollo natural de las personas en sociedad.

Este mismo autor también se refiere a la cultura como las actividades más refinadas que los individuos han extraído del trabajo y de la agricultura; esto significa que además de las costumbres, tradiciones y hábitos, dentro de la cultura están inmersas también aquellas prácticas agrícolas que el hombre realiza para la consecución de su alimento, que van desde la obtención de semillas, el tratamiento del suelo, siembra y cosecha, hasta llegar a la preparación de sus alimentos (gastronomía). 
En sí que, cuando nos referimos a la cultura, hablamos de la identidad de un pueblo como aquella riqueza que les permite diferenciarse unos de otros. Al perderse esa identidad se pierde la valiosa historia que los antepasados les dejaron a sus descendientes, volviéndose vulnerables al adoptar nuevos pensamientos e ideologías de sociedades ajenas a ellos. Por tal motivo este ensayo tiene como objetivo revalorizar el bagaje cultural de las principales culturas aborígenes del Ecuador con la finalidad de preservar las bases históricas y culturales de cada región del país.

\section{Desarrollo}

\subsection{La realidad del pueblo latinoamericano}

Las naciones que conformaban el Tahuantinsuyo, buscan el reconocimiento de su derecho ancestral, para ello es necesario rescatar las costumbres y tradiciones, las mismas que forman parte de su patrimonio cultural, por ello hay que encaminarse hacia la búsqueda del legado perdido comenzando de esta manera el proceso de desintoxicación colonial y reforzando la identidad. Conforme a lo expresado por Tibán (2009): "para reforzar la identidad de los pueblos y de las personas en las épocas de crisis es necesario [...] re-descubrir y valorizar sus características como pueblo [...]" (pág. 3); cuando la sociedad se acerca a su pasado, se enriquece su historia.

Para que los ecuatorianos puedan recuperar su identidad, deben tener conocimiento de su propia cultura ancestral y darle el verdadero valor a su gran patrimonio. Las costumbres, fiestas tradicionales, arte, gastronomía, productos autóctonos, saberes ancestrales y las distintas prácticas como los rituales de siembra y cosecha, deben ser restaurados bajo una visión de pertenencia, que permita desechar arraigos de vergüenza ante lo propio e integre en las nuevas generaciones el amor por su identidad como pueblo de raíces atávicas. 
Instituto Internacional de Investigación y Desarrollo Tecnológico Educativo INDTEC, C.A.

DOI: https://doi.org/10.29394/Scientific.issn.2542-2987.2021.6.21.18.336-355

OAI-PMH: http://www.indteca.com/ojs/index.php/Revista Scientific/oai

Ensayo Original / Original Essay

\subsection{La cultura y su relación con la naturaleza en los tiempos aborígenes}

La cultura para el antropólogo Tylor, citado por Grimson (2008): quien definió este término en el año 1871, está asociado a los conocimientos, creencias y hábitos que el ser humano adquiere como miembro de la sociedad. Por su parte, Tylor (1871), citado por Harris (2016), describe la definición de Tylor como:

La cultura... en su sentido etnográfico, es ese todo complejo que comprende conocimientos, creencias, arte, moral, derecho, costumbres y cualesquiera otras capacidades y hábitos adquiridos por el hombre en tanto que miembro de la sociedad. La condición de la cultura en las diversas sociedades de la humanidad, en la medida en que puede ser investigada según principios generales, constituye un tema apto para el estudio de las leyes del pensamiento y la acción humana (pág. $4)$.

Los aborígenes tenían un sumo respeto a la naturaleza, ya que de ella obtenían la materia prima para su sustento, como indica el Instituto de Relaciones Internacionales (IRI, 2013): "el valor de la naturaleza como proveedora de recursos para el sostenimiento de la vida humana [...]" (pág. 5); conforme a Estrada (2009): para la civilización Inca, la naturaleza era sagrada, al igual que para los mayas quienes heredaron a sus sucesores la tradición milenaria de observación de la naturaleza.

En este sentido, Montañez y Martinez (2013): mencionan que las culturas de América tenían un lazo estrecho con la naturaleza, nunca fue de superioridad, sino más bien era como si formara parte de ellos mismos, tanto que, antes de derribar un árbol le pedían perdón y una vez cortado le rendían servicios funerarios, ya que creían que en algún momento las plantas, animales y minerales habían sido semejantes al hombre.

Pero ¿Cuándo se advierte este cambio de admiración hacia la naturaleza por ser quien suple las necesidades del hombre?; ¿Cómo se produce la ruptura de esa estrecha relación de coexistencia?. Mencionando a 
Instituto Internacional de Investigación y Desarrollo Tecnológico Educativo INDTEC, C.A. DOI: https://doi.org/10.29394/Scientific.issn.2542-2987.2021.6.21.18.336-355

OAI-PMH: http://www.indteca.com/ojs/index.php/Revista Scientific/oai

Ensayo Original / Original Essay

Castillo, Suárez y Mosquera (2017):

La agricultura y el sedentarismo determinan características particulares en la interacción ser humano-naturaleza, la cual se orienta hacia la necesidad de proveer una mayor cantidad de alimentos y mejores condiciones de vida para las poblaciones crecientes, lo que incide en el cambio del uso del suelo, la afectación de la diversidad biológica en las plantas y los animales, el consumo de materias primas para la vivienda y la vestimenta (pág. 350).

La ruptura de la visión cosmológica del hombre, de la conexión hombrenaturaleza, se advierte en la forma de utilización del ecosistema después de la conquista, es decir en el uso de la tierra (cultivos y ganadería). Señalando a la perspectiva de Ayala (2008): "con la llegada de la expedición de Cristóbal Colón y el inicio de la subyugación violenta de los pueblos aborígenes comenzó una época nueva para nuestro continente" (pág. 12); afectando no solo a nuestra etnia, sino también a nuestro ecosistema, ya que, aunque se mantuvo el cultivo familiar, ciertos productos extranjeros fueron insertados en los cultivos y por ende modificó la cocina indígena, además de la aplicación de técnicas de cocción diferentes, dando lugar a la cocina fusión.

De acuerdo con Serrano, et al. (1990a): antes de la llegada de los europeos, los indígenas obtenían su sabiduría de la naturaleza, cultivaron alrededor de 300 plantas medicinales y alimenticias, las mismas que en la actualidad casi no existen, debido a que han sido sustituidas por alimentos y medicinas con componentes químicos.

Desde la conquista, los descendientes indígenas han tratado de mantener ciertas costumbres y tradiciones, entre ellas la agricultura familiar, pero de acuerdo a Rosero, Carbonell y Regalado (2011): en la actualidad el proceso productivo agrícola sigue enfocado en la acumulación de capital y sistemas productivos de monocultivo alineados a la exportación, lo que da lugar a que la agricultura en el Ecuador y sus políticas públicas apoyen al 
sector agroindustrial dejando a un lado el apoyo de la agricultura familiar y campesina que, a criterio de Jordán (1988): con la intervención del gobierno ha sido circunstancial y fragmentada desde hace muchos años. En palabras de Serrano, et al. (1990b):

Ahora que la contaminación del suelo, el aire, el agua y los alimentos llegan a niveles alarmantes y están en peligro las bases mismas de nuestra existencia, se hace necesario mirar hacia atrás a fin de encontrar caminos y opciones para la práctica de una nueva agricultura [...] (pág. 333).

Esta nueva forma de agricultura debe ser productiva y restablecer el equilibrio biológico de nuestro entorno, siendo esta la mejor oportunidad de recuperar en algo los vestigios de nuestra cultura, basados en la creencia de Rosa, Bellelli y Bakhurst (2008): de que "[...] los recuerdos del pasado contribuyen a la creación de Identidad" (pág. 170).

\subsection{Culturas Región Costa: Manteño Huancavilca - Milagro Quevedo}

Los españoles evidenciaron el desarrollo alcanzado por los colectivos asentados en las costas ecuatorianas: los Manteño Huancavilcas y los Chonos. Como dice Zevallos (1995), citado por Vargas (2014):

La Provincia de los Guancavilcas, según Benzoni, comenzaba desde Colonche, al norte de la actual provincia del Guayas, extendiéndose por toda la zona situada al oeste y sur de la Cordillera Chongón-Colonche. Al momento de la conquista española se encontraban en proceso de expansión, infiltrando su cultura por la cuenca húmeda del Guayas, en el área de ocupación Chona (pág. 6).

Por su parte, Regalado (2019a): detalla que los informes de la investigadora Mercedes Guinea, en las excavaciones del año 1974 de un yacimiento de la cultura Atacames, hallaron un cuenco con restos de un guiso de pescado con maíz, conservado adecuadamente gracias al proceso de carbonización parcial. También presenta Regalado (2019b): que se encontró 
"[..] una olla grande y alrededor de ella 200 cuencos pequeños para tomar chicha o una bebida especial en alguna fiesta o ritual" (pág. 21). A juzgar por estas evidencias arqueológicas halladas en la costa, nuestros antepasados cultivaban el maíz y se consumían productos con base en este.

La cultura Milagro-Quevedo fue la que más territorio ocupó, su asentamiento se dio en el sistema fluvial del Guayas, incluyendo sus dos grandes ríos, Daule y Babahoyo y todos sus afluentes. Cabe recalcar que la ciudad de Guayaquil es considerado territorio Milagro-Quevedo, definidos étnicamente como Chonos. Esta cultura se dedicaba a la orfebrería, realizaban trabajos elaborados en oro y plata.

En su adorno personal estaban los aretes, se colocaban seis en cada oreja, tanto en el lóbulo como en el pabellón. Lo más característico fue la construcción de tolas. Según lo descrito por Guamán (2015): tenían buenas relaciones comerciales y culturales ya que existen tumbas de los Chonos (Milagro-Quevedo) en la zona en que se desarrollaba la cultura ManteñoHuancavilca, así como objetos andinos en tumbas quevedeñas. Los chonos realizaban sus cultivos en albarradas y camellones, sobre esto, Pazos (2008), señala que:

La cultura Milagro-Quevedo perfeccionó esta técnica. Los camellones son bancos construidos en terreno anegadizo que se van alternando con zanjas que los limitan. Según la altura, en los camellones se sembraban maíz, fréjol, yuca, etc., mientras otras plantas crecían en la zanja, donde también vivían peces y otros animales (pág. 111).

Por su parte, Willey (1971), citado por Serrano, et al. (1990c): reafirma esta idea en referencia a la extensión de los movimientos de tierra que "[...] consisten de camellones de aproximadamente de 9 a 12 metros de ancho, y en algunos casos, de varios kilómetros de largo" (pág. 104). En conformidad con Holm (1981): "encontramos estas construcciones desde las llanuras anegadizas en la región amazónica de Bolivia, en Mojos, a orillas del lago 
Instituto Internacional de Investigación y Desarrollo Tecnológico Educativo INDTEC, C.A.

DOI: https://doi.org/10.29394/Scientific.issn.2542-2987.2021.6.21.18.336-355

OAI-PMH: http://www.indteca.com/ojs/index.php/Revista Scientific/oai

Ensayo Original / Original Essay

Titicaca, también con Colombia, Venezuela, Surinam, México y hasta en el valle de Mississipí, EE.UU." (pág. 32); pudiendo tratarse de convergencias culturales, de estímulos o de contactos culturales.

\subsection{Cultura Región Sierra: Caranqui}

Considerando a Ugalde y Landázuri (2016): la cultura Caranqui corresponde a una sociedad compleja desarrollada en el periodo de Integración Tardío (700 - 1500 d.C.) de la época preincaica, se asentó en la porción de la Sierra norte del Ecuador, entre los ríos Chota - Mira por el norte y Guayllabamba por el sur, que corresponden a las actuales provincias de Imbabura y Pichincha habiendo ocupado un área de alrededor de $3600 \mathrm{~km}$. Interpretando a Perez (1975a): esta cultura se distinguió por la construcción de tolas o montículos artificiales para sepultura, sus objetos de barro eran grandes vasijas, platos con patas de trípode y otros en forma de zapato.

En lo referente a la producción agrícola, Oberem (1981): describe que en las grandes partes de la sierra ecuatoriana se practicaba la "microverticalidad quiere decir que los habitantes de un pueblo tenían campos situados en diferentes pisos ecológicos alcanzables en un mismo día con la posibilidad de regresar al lugar de residencia por la noche" (pág. 51); razón por la cual tenían varios productos de diferentes ecologías. Al respecto, Plháková (2010): añade que, para el cambio de los alimentos cultivados tenían también sus comerciantes 0 mindalaes que se encargaban de las transacciones.

Acorde con esto, Gondard (2006): dice que los grupos prehispánicos construyeron camellones de cultivos, aumentando los relieves naturales, mientras que el riego lo realizaban mediante canales o drenaje de lagos. E cultivo de la tierra se hacía con artefactos rudimentarios de madera y piedra, lo cual les permitía cosechar frutos y vegetales variados que solo se producían en la región gracias a la particularidad del clima y la tierra. 


\subsection{Cultura Región Oriental: Shuar}

Adicionalmente, Perez (1975b): destaca que, los Shuar constituyen un grupo indígena existente en la selva amazónica de Ecuador y Perú, conocido también como jibaros. Su alimentación está basa en la agricultura, caza y pesca. Los métodos de cultivo eran la roza y quema. Comían animales domésticos (puercos, galleas) así como otros animales que cazaban (cerdo y pavos salvajes, monos, guacamayos, pájaros pequeños, entre otros). El pescado es otro tipo de alimento importante. En este orden de ideas, Karsten (2000), nos indica sobre las frutas comestibles de los shuar lo siguiente:

El único árbol que produce frutas comestibles, cultivado por los Jívaros, es la palma de chontarúru (guilielma), llamada uí por los Jívaros [...] esta especie de manzana roja no puede ser comida cruda y es siempre hervida en agua. [...] La selva virgen del Amazonas occidental produce pocos frutos comestibles y alimentos vegetales para ofrecer a los nativos [...] (pág. 106).

Los alimentos con mayor producción son la yuca y el plátano, aunque también cultivan camote, kingi, maíz, una clase de zanahoria, maní, legumbres y caña de azúcar. En cuanto a registros de la gastronomía de las cocinas del oriente ecuatoriano y de la región insular (Galápagos), se puede decir que son escasas o nulas, por ello Unigarro (2010):

[...] Plantea la imperiosa necesidad de promover estudios en orden a conocer a profundidad las técnicas y elaboraciones de sus cocinas, que indudablemente poseen una riqueza extraordinaria que espera ser explorada pero que hoy aparece marginal o invisible en la percepción de sus patrimonios alimentarios (pág. 132).

Cabe recalcar que los Shuar todavía se mantienen existentes en el oriente ecuatoriano, su cosmovisión es la de vivir en completa armonía con la naturaleza, ya que esta es quien provee los alimentos que ellos consumen. 


\section{Ensayo Original / Original Essay}

\subsection{Conquista española}

En Mesoamérica y los Andes se centró la conquista de América, debido a que allí se encontraban asentados los imperios azteca e inca. Los colonizadores rápidamente subyugaron a los pueblos que tenían una vida agrícola organizada, debido a que estas sociedades atravesaban crisis internas y pasaban por fuertes enfermedades. En referencia al tema, Ayala (2017), ratifica que:

[...] Los pueblos de la Sierra fueron sometidos rápidamente [...] Algunos de la Costa se sometieron y otros se adentraron en tierras a las que los colonizadores llegaron siglos después. Al principio los conquistadores se valieron de los caciques para consolidar su control, pero a fines del siglo XVI lograron establecer una estructura colonial. Los pueblos amazónicos no fueron conquistados. Su contacto con la sociedad colonial fue reducido, pero los impactó (pág. 24).

La gran guerra que se dio entre colonizadores e indígenas tanto de la costa y sierra, termina con el sometimiento de los aborígenes. Por su parte, Rendón (1967), citado por Meyers (1998a), quién destaca que:

1'100.000 personas de la población puramente indígena "sobrevivieron" a la conquista española. La mayor parte corresponde a los indígenas de la Sierra, mientras que, con toda seguridad, no se incluye todos los grupos del Oriente. En el litoral existen únicamente algunos grupos restantes. El problema complejo de la desaparición más acelerada de la mayoría de las tribus indígenas de la Costa, después de la conquista española, no puede ser aquí tratado. Se puede suponer, sin embargo, que el número de habitantes de esta zona, en el momento de la conquista, fue más reducido que el de la Sierra (pág. 21).

Las condiciones ecológicas de la costa ecuatoriana fueron desfavorables tanto para los incas como para los conquistadores, por obvias razones el litoral era una jurisdicción poco atractiva debido a que era zona húmeda tropical, tierra caliente con temperatura de 22 a $26{ }^{\circ} \mathrm{C}$ y casi todo el 
año lluvioso, con exuberante vegetación en manglares, palmeras, alternadas con plantaciones de cacao, banano y café. Adicionalmente, Meyers (1998b): afirma que la región andina fue la predilecta, lo cual permitió que se enriqueciera la cocina indígena, tanto con los productos de los incas como con la variedad de productos que trajeron los españoles.

\subsection{Identidad cultural y rescate de los saberes ancestrales}

La identidad cultural para Mac Gregor (2013): se desarrolla con la reproducción de las prácticas cotidianas y los rituales que pertenecen a una comunidad, los mismos que son parte de los saberes ancestrales de nuestros antepasados. Este cúmulo de conocimientos y valores han sido transmitidos de generación en generación, pero en la actualidad se han visto afectados debido a la globalización y la aculturación. Para Herrera y Muñoz (2019): "no se puede hablar de la globalización, el modernismo y el capitalismo como los factores que destruyen la cultura alimentaria regional o autóctona, sino como los detonantes a la búsqueda de la identidad materializada en la cocina nacional" (págs. 13-14).

Lo cierto es, que la globalización y aculturación han afectado directamente a nuestra identidad debido a que se han insertado tanto en la vida cotidiana del ser humano, que, adoptando culturas extranjeras, asume como propias, costumbres y tradiciones del exterior, teniendo muchas veces vergüenza de la propia, y creando un sentido de falta de pertenencia en la sociedad.

Un ejemplo de esta realidad es la preferencia de productos extranjeros o industrializados en los supermercados antes de preferir nuestros productos autóctonos, esto conlleva a una baja producción de productos locales y que por ende el agricultor deje de producirlos, afectando directamente a la valoración de nuestra gastronomía, perdiendo los sabores originales de nuestros pueblos ancestrales. 


\section{Conclusiones}

Los países del Tercer Mundo debido a la globalización han tratado de imitar los procesos de las naciones industrializadas, con la finalidad de un cambio rápido que permita mejorar su situación económica y social, dejando de lado sus propios procesos históricos. Estos cambios se pueden observar en la importación de tecnologías, en aperturas de grandes plantas industriales, así como también en el reemplazo de sus tradiciones autóctonas por otras costumbres que van asimilando como sociedad en función de la influencia impuesta por las redes sociales y la viralización de la información.

Ecuador, con la finalidad de recuperar su identidad, ha ido creando leyes en función de rescatar, tanto a nivel cultural como económico, el desarrollo de los individuos con base en las tradiciones que generen emprendimientos con marca nacional, pero aunque estas leyes no se cumplen a cabalidad; y entre los mismos actores de los procesos se coarten muchas veces estas intenciones, es importante destacar que depende de cada individuo, el valorar su historia, sentirse orgulloso de su legado y reproducirlo a nivel nacional e internacional.

Las políticas públicas en educación deben guiar de manera coherente esos procesos de revalorización, para lograr a corto plazo que las nuevas generaciones retomen el camino hacia ella. Hay que recordar que la pérdida de identidad implica disipar tradiciones, costumbres, memorias, gastronomía y diversidad, todo enlazado entre sí en una cadena circular. Por ello, al hablar, por ejemplo, de alimento y gastronomía se deben tomar en cuenta todas las prácticas ancestrales que conllevan a su consumo y adquisición.

La cocina ecuatoriana fue uno de los aspectos culturales que en mayor proporción se vio alterada con la conquista española, ya que con la introducción de nuevos productos nació la comida criolla. Es evidente que la gastronomía ecuatoriana dio un giro de $180^{\circ}$ ya que se enriqueció en variedad, sabor y técnicas, pero así mismo, hay que ser conscientes que se perdieron 
Ensayo Original / Original Essay

tradiciones, se fracturó la armonía con la naturaleza, dejando a un lado esa conexión con el mundo natural que nos rodea. La madre tierra dejó de ser esa gran conexión con el humano que lo cura y paso a ser quien soporta destrucciones porque no siente.

\section{Referencias}

Ayala, E. (2017). Ecuador Patria de todos: identidad nacional, interculturalidad e integración. ISBN: 978-9978-84-964-4. Quito, Ecuador: Corporación Editora Nacional, CEN; Universidad Andina Simón Bolívar, Sede Ecuador. Recuperado de:

http://hdl.handle.net/10644/7169

Ayala, E. (2008). Resumen de Historia del Ecuador. Tercera edición actualizada, ISBN: 978-9978-84-477-9. Quito, Ecuador: Corporación Editora Nacional.

Castillo, A., Suárez, J., \& Mosquera, J. (2017). Naturaleza y Sociedad: Relaciones y tendencias desde un enfoque eurocéntrico. Luna Azul, (44), 348-371, e-ISSN: 1909-2474. Recuperado de: https://revistasojs.ucaldas.edu.co/index.php/lunazul/article/view/3842

Eagleton, T. (2000). La idea de cultura: Una mirada política sobre conflictos culturales. ISBN: 84-493-1096-2. Barcelona, España: Ediciones Paidós Ibérica.

Estrada, A. (2009). Naturaleza, cultura e identidad. Reflexiones desde la tradición oral maya contemporánea. Estudios de Cultura Maya, 34(1), 181-201, e-ISSN: 2448-5179. Recuperado de:

https://dialnet.unirioja.es/servlet/articulo?codigo $=5627813$

Gondard, P. (2006). Campos elevados en Ilanuras humedas del modelado al paisaje: camellones, waru warus o pijales. En Valdez, F. (ed.). Agricultura Ancestral. Camellones y Albarradas: Contexto social, usos y retos del pasado y el presente. (págs. 25-53). ISBN: 9978-22-563-3. 
Quito, Ecuador: Abya-Yala; IFEA.

Grimson, A. (2008). Diversidad y cultura. Reificación y situacionalidad.

Tabula Rasa, (8), 45-67, e-ISSN: 1794-2489. Recuperado de: https://www.redalyc.org/articulo.oa?id=39600803

Guamán, O. (2015). Orígenes e historia del arte precolombino en Ecuador. ISBN: 978-9942-24-015-6. Machala, Ecuador: Universidad Técnica de Machala. Recuperado de:

http://repositorio.utmachala.edu.ec/handle/48000/6805

Harris, M. (2016). Antropología cultural. Madrid, España: Alianza editorial. Herrera, T., \& Muñoz, D. (2019). La Revalorización de los Alimentos Ancestrales Ecuatorianos. Trabajo de titulación. Quito, Ecuador:

Universidad San Francisco de Quito - USFQ. Recuperado de: http://repositorio.usfq.edu.ec/handle/23000/8150

Holm, O. (1981). Cultura Milagro - Quevedo. Guayaquil, Ecuador: Guayaquil, Ecuador: Banco Central del Ecuador. Recuperado de: http://www.dspace.uce.edu.ec/handle/25000/17928

IRI (2013). La relación entre los seres humanos y la naturaleza: construcción, actualidad y proyecciones de un peligro ambiental. ISSN: 2344-956X. Buenos Aires, Argentina: Instituto de Relaciones Internacionales; Facultad de Ciencias Jurídicas y Sociales, Universidad Nacional de La Plata.

Jordán, F. (1988). El minifundio: su evolución en el Ecuador. ISBN: 9789978958087. Quito, Ecuador: Corporación Editora Nacional.

Karsten, R. (2000). La vida y la cultura de los shuar. Segunda edición en español, ISBN: 9978-04-602-X. Quito, Ecuador: Ediciones Abya-Yala.

Mac Gregor, J. (2013). Identidad y Globalización. Cuadernos. México: Patrimonio Cultural y Turismo.

Meyers, A. (1998a,b). Incas en el Ecuador: Análisis de los restos materiales. 1 parte, ISBN: 9978-72-077-4; ISBN: 9978-04-310-1. 
Ecuador: Ediciones del Banco Central del Quito, Ecuador; Ediciones Abya-Yala.

Montañez, A., \& Martinez, R. (2013). La naturaleza como víctima de la conquista Española caso: los murciélagos. Telos, 15(2), 153-164, eISSN: 1317-0570. Recuperado de:

https://www.redalyc.org/articulo.oa?id=99328423002

Oberem, U. (1981). "Indios libres" e "indios sujetos a haciendas" en la sierra ecuatoriana a fines de la colonia. En Moreno, S., \& Oberem, U. Contribución a la etnohistoria ecuatoriana. (págs. 45-71). Otavalo, Ecuador: Editorial Gallocapitán.

Pazos, J. (2008). El sabor de la memoria: historia de la cocina quiteña. ISBN: 978-9978-366-02-8. Quito, Ecuador: FONSAL.

Perez, A. (1975a,b). Cartilla de divulgación ecuatoriana No. 1. Las culturas aborígenes de la República de Ecuador. Quito, Ecuador: Casa de la Cultura Ecuatoriana. Recuperado de:

http://repositorio.casadelacultura.gob.ec/handle/34000/19048

Plháková, A. (2010). Las etnias indígenas del Ecuador. Tesis. Olomouc, República Checa: Palacký University Olomouc. Recuperado de: https://theses.cz/id/stcsni/

Regalado, L. (2019a,b). Manabí y su comida milenaria. Segunda edición, ISBN: 978-9942-775-58-0. Manta, Ecuador: Departamento de Edición y Publicación Universitaria (DEPU); Ediciones Uleam.

Ron, J. (1977). Sobre el concepto de cultura. Cuadernos culturales. Quito, Ecuador: IADAP; Ediciones Solitierra.

Rosa, A., Bellelli, G., \& Bakhurst, D. (2008). Representaciones del pasado, cultura personal e identidad nacional. Educação e Pesquisa, 34(1), 167-195, e-ISSN: 1678-4634. Recuperado de:

https://www.revistas.usp.br/ep/article/view/28083

Rosero, F., Carbonell, Y., \& Regalado, F. (2011). Soberanía alimentaria, 
modelos de desarrollo y tierras en Ecuador. Primera edición. Quito, Ecuador: CAFOLIS-Grupo Apoyo.

Serrano, V., Gordillo, R., Guerra, S., Naranjo, M., Costales, P., Costales, A., ... Astudillo, L. (1990a,b,c). Ciencia Andina. 2da. Edición, ISBN: 997804-519-8. Quito, Ecuador: Ediciones Abya-Yala.

Tibán, Á. (2009). Identidad, cultura y género. Quito, Ecuador: Escuela de Formación Política del MICC; Instituto de Estudios Ecuatorianos - IEE. Ugalde, M., \& Landázuri, C. (2016). Sociedades heterárquicas en el Ecuador preincaico: estudio diacrónico de la organización política caranqui. Revista Española de Antropología Americana, 46, 197-218, e-ISSN: 0556-6533. Recuperado de:

https://doi.org/10.5209/REAA.58294

Unigarro, C. (2010). Patrimonio cultural alimentario. Primera edición. Quito, Ecuador: Cartografía de la Memoria.

Vargas, M. (2014). Registro y puesta en valor del patrimonio de la cultura manteña de los cerros hojas, jaboncillo, negrita, bravo y guayabal. Ecuador: Centro de Investigación Hojas - Jaboncillo. 


\section{Ensayo Original / Original Essay}

\section{María Elena Guerrero Salazar}

e-mail: maria.guerreros@ug.edu.ec

Nacida en Guayaquil, Ecuador, el 21 de octubre del año

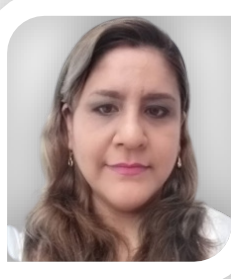
1980. Licenciada en Gastronomía en la Universidad de Guayaquil (UG), graduada con excelencia académica (Medalla de la Benemérita Sociedad Filantrópica del Guayas); Cursé el Diplomado de Agrodiversidad y Soberanía Alimentaria en el Instituto para el Desarrollo Sustentable en Mesoamérica, A.C. (IDESMAC), México; además de un curso de postgrado internacional virtual "Saberes y tradiciones - Plantas subutilizadas de la Zona Andina", dictado por la Universidad Mayor de San Andrés (UMSA), La Paz, Bolivia; y la Red Iberoamericana de Cultivos CultIVACYTED. Investigadora en el campo de la innovación agrícola y la gastronomía. Coautora de la guía de Epistemología del Marketing publicada en el año 2018 con el con ISBN: 978-9942-757-29-6, por la Editorial Ulink. 


\section{Ensayo Original / Original Essay}

\section{Verónica Paulina Pilaquinga Cantuña}

e-mail: paulip84@hotmail.com

Nacida en la Ciudad de Quito, Ecuador, el 28 de marzo del

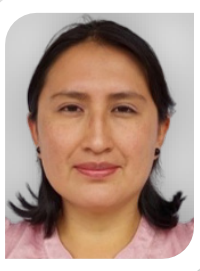
año 1984. Ingeniera Agrónoma, graduada en la Escuela de Agricultura de la Región Tropical Húmeda (Universidad EARTH), Costa Rica; me he desempeñado en análisis financiero y elaboración de proyectos en el sector público y privado; realicé extensionismo en las Escuelas de la Revolución Agraria del Ministerio de Agricultura; en Agrocalidad me desempeñe como Analista Fitosanitaria y de Inocuidad de Alimentos; ha desarrollado programas y proyectos para el control de plagas de importancia económica; elaboración de Guías y Manuales de Buenas Prácticas Agrícolas; actualmente soy analista de Insumos Agrícolas y me encuentro desarrollando un Proyecto de Análisis de Riesgo en el marco del Convenio de Rotterdam. 


\section{Ensayo Original / Original Essay}

\section{Christian Virgilio Guerrero Salazar \\ e-mail: chguerrero.ascaped@gmail.com}

Nacido en Guayaquil, Ecuador, el 8 de julio del año 1977.

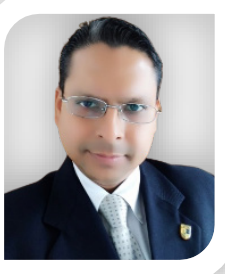

Licenciado en Ciencias de la Educación, Especialización

FIMA de la Facultad de Filosofía, Letras y Ciencias de la Educación de la Universidad de Guayaquil (UG); Maestría en Educación de la Universidad Tecnológica Empresarial de Guayaquil (UTEG); tengo una experiencia docente de 23 años colaborando con distintas instituciones de educación media y superior en la ciudad de Guayaquil; soy director pedagógico de Asesoría y Capacitación Pedagógica (ASCAPED), empresa dedicada a la capacitación y asesoría educativa; también me desempeño como docente y gestor pedagógico en la Unidad Educativa Bilingüe Torremar; he colaborado durante varios años con diferentes Universidades, fundaciones y editoriales ecuatorianas como capacitador docente, asesor pedagógico, investigador, itemólogo y metodólogo; soy consultor en el área pedagógica e instructor de cursos de formación de la Organización de Estados Iberoamericanos (OEI); he participado en varios eventos nacionales e internacionales como ponente; cuento con variadas publicaciones en revistas indexadas.

El contenido de este manuscrito se difunde bajo una Licencia de Creative Commons ReconocimientoNoComercial-Compartirlgual 4.0 Internacional 